\title{
Monetary Policy and Liquidity of Vietnam's Stock Market
}

\author{
TRAN THI HAI LY \\ University of Economics HCMC - hailyth@ueh.edu.vn
}

\section{ARTICLE INFO ABSTRACT}

Article history:

Received:

May. 06. 2015

Received in revised form:

May. 16. 2015

Accepted:

Mar. 252016

Keywords:

Liquidity, monetary

policy.
This study investigates the impact of monetary policy on liquidity of Vietnam's stock market from September 2007 to November 2014. Time series of liquidity are determined by monthly liquidity data for 643 enterprises in the surveyed period. Two variables of the monetary policy, including growth in money supply and interbank rate, are employed in VAR model along with four different measures of market liquidity. The results show that unexpected variance in the two monetary policy variables has no significant impact on the market liquidity, which, in turn, may be improved by the positive shocks of market returns, inflation, and growth in industrial production. Market variance does produce certain effects, but discrepancies occur in the signs of various liquidity measures. 


\section{Introduction}

Prior studies on liquidity mainly centered on the development of liquidity measures in various markets ranging from developed to emerging stock securities and examined whether liquidity should be one of the risk components in asset pricing models as well as its determinants.

At the market level the issue of liquidity becomes increasingly critical, particularly amid the shocks it has ever suffered during the past two decades. Evidently, policy makers have made a move to impact on liquidity owing to its importance attached to efficiency of financial market and prosperity of the economy (Chordia et al., 2008). Recent studies also focus more on market-level time series data and inspect a variety of macro factors with influence on liquidity such as inflation, growth, and monetary policy (Brunnermeier \& Pedersen, 2009; Fernández-Amador et al., 2013; Chordia et al., 2005; Choi \& Cook, 2006; Goyenko \& Ukhov, 2009).

A few Vietnamese researchers (Do, 2010; Nguyen, 2012), in examining liquidity at the market level, detected liquidity of Vietnam's stock market being at its low rates. Yet, certain research on a consistent basis into the impact of monetary policy factors on liquidity has yet to be conducted. In many countries of the world the monetary policy does exert immediate effects on liquidity across the market, and a move by the central bank to control interest rates and money supply instantly alters liquidity (Jawadi et al., 2010). Accordingly, either the US Federal Reserve or the European Central Bank has often ultilized the power of monetary policy tools in improving market liquidity or minimizing its depletion upon the occurrence of financial instability.

Nevertheless, regulations differ accross the nations on the use of margin accounts or credit institutions' financing stock investments, which is subject to potential different levels of policy impact in different markets. More specifically, SBV's regulations on capital financing for stock investments are quite distinct, such as securities lending amount, which must not exceed $20 \%$ of charter capital, or the recently applied margin trading. It is thus necessary to research into the effects of monetary policy on the liquidity of Vietnam's market, the findings of which would specify the efficiency of the policy and also offer further implications. 


\section{Theories of liquidity and impact of monetary policy}

\subsection{Liquidity of stock market}

Liquidity is an abstract concept, which can be defined in multiple ways. In the simplest terms liquidity essentially refers to the ease of trading a particular financial security, whereas only when the corresponding transaction costs are minimized is a market characterized as being highly liquid. Constituents of liquidity encompass costs of searching for trading partners and other costs of inventory risk inherent in transaction delays, market imperfections, and adverse selection risk (Kyle, 1985).

Based on these arguments, researchers have developed different liquidity measures, each of which targets a specific perspective with regard to its definitions. While Amihud (2002) measured sensitivity of small stock returns to market illiquidity, Lesmond et al. (1999) based their estimation of transaction costs on the incidence of zero returns in addition to Roll's (1984) calculation of effective bid-ask spread.

\subsection{Effects of monetary policy on liquidity}

Monetary variables are the first to have certain impacts on liquidity. Brunnermeier and Pedersen (2009) maintained that the stock market is theoretically expected to have higher liquidity if its participants gain access to cheaper financing for their investments or when they could perceive the lower risk of holding assets. As the monetary policy does affect both costs of financing and the stated risk, it also influences market liquidity. Regulations on margin trading restrictions are available in the market; liquidity of financing sources and assets are closely interrelated. Clearly, the traders who face capital shortage might meet with difficulties in satisfying margin trading requirements, thus being incapable of providing liquidity for the market.

To this extent the loosening of monetary policy would support market liquidity and vice versa. Fernández-Amado et al. (2013) hypothesized that the monetary policy is one of the key factors affecting stock market liquidity and employed the inventory paradigm of the market microstructure literature to confirm their hypotheses. As such, when the market supply pressure is too intense, the market makers would stand ready to acquire stock for liquidity producing efforts.

However, due to the possible risk of price fluctuations during stock acquisition up to the period when partners could be found to rebalance their position, the market makers require a risk premium; thus, the higher costs of financing for asset holdings, the larger 
the premium. Following this reasoning, the stock will become more liquid if market participants can access cheaper financing sources for their porfolios and see the market from a low risk perspective. Since the direct impact is exerted by monetary policy on the costs of capital along with different viewpoints on market risk, it is more likely for the monetary policy to have effects on liquidity. Empirical findings by Fernández-Amado et al. (2013) suggested that expansionary monetary policy alleviates constraints for margin borrowing, conditions the funding liquidity, and therefore entails the improvements in market liquidity.

The findings from other empirical studies also asserted that loosening (tightening) monetary policy could be associated with an increase (reduction) in market liquidity. Chordia et al. (2001) observed that a rise in short-term federal funds rate leads to liquidity decline, whereas expansionary monetary policy is suggested to escalate market liquidity, and unexpected increased federal fund rate results in decreases in liquidity (Chordia et al., 2005). Although Goyenko and Ukhov (2009) implied that tightening monetary policy forecasts an increase in market illiquidity, it is pointed out by Choi and Cook (2006) that shocks of monetary policy variables have no effects on the liquidity of the Japanese market. Liquidity shocks, nevertheless, do influence the monetary policy and other macroeconomic variables.

Accordingly, most previous research confirms that the tightening of monetary policy exacerbates market liquidity, yet it remains uncertain whether similar empirical evidence could be found in Vietnam's market due to SBV's quite distinct regulations as formerly stated. An investigation into the nexus between its monetary policy and liquidity is of vital importance as the key to a puzzle.

The following macro factors, besides the monetary policy variables, are also found to have effects on market liquidity.

\section{Industrial production}

Eisfeldt (2004) argued that an economy with high productivity will be conducive to higher risk of investments in assets, and for such a reason portfolio rebalancing occurs more frequently, thereby mitigating the risk of adverse selection and inducing liquidity increase. In empirical aspects, several scholars have recently found liquidity to be related to various macro-economic conditions (Choi \& Cook, 2006; Fernandez-Amador et al., 2013). 


\section{Inflation}

Inflation is expected to have adverse influence on liquidity since an increase in the positive shock of inflation may raise investors' awareness of risk. Goyenko and Ukhov (2009) explored CPI with its causal impact on stock liquidity. A shock of CPI would boost the rates of market illiquidity, as prescribed by scholars, indicating an increase in costs of processing orders and inventory holdings due to inflation reflected in higher costs of trading. Alrabadi (2012) found no evidence relating to the effects of inflation as a macroeconomic variable on spread and depth measures, but trading activity measures are highly affected. To the same extent, Fernandez-Amador et al. (2013) offered inconsistent findings on effects of inflation of previous terms on stock liquidity. As such, increased inflation enlarges the measures of price impact, reducing the trading volume (reduced liquidity) while increasing the turnover rate (increased liquidity).

\section{Rate of returns}

From a logical point of view scholars suggested an impact of liquidity on rate of returns through a large compensation required by investors in the event of higher costs of trading (Amihud \& Mendelson, 1986). In the context with the presence of irrational investors Baker and Stein (2004) developed a model to clarify why lower returns would be predicted by an increase in liquidity in both firm-level and aggregate data. A liquidity improvement, as reported by Watanabe (2004), manifests itself when a shock of increased market returns exists. Rhee and Wang (2009) found rather consistent effects of returns on liquidity and demonstrated that the rate of returns reduces price spread and sensitivity but increases stock depth.

\section{Volatility of returns}

Volatility reflects the perspective of risk faced by liquidity providers in the market. Benston and Hagerman (1974) implicated the impact of volatility on liquidity based on the reasoning that an increase in volatility implies increased inventory risk and thus causes a higher bid-ask spread. Copeland and Galai (1983) maintained that standard deviation of returns occupies an important position in bid-ask spread change.

Conversely, a liquidity decline may entail increased price volatility (Subrahmanyam, 1994). Standard deviation is empirically found to cause decreases in liquidity (Goyenko \& Ukhov, 2009), whereas as for Chordia et al. (2005), a bid-ask spread is encouraged by a shock of standard deviation. Kale and Loon (2011) detected a positive relation between standard deviation of stock returns and illiquidity measures. Meanwhile, 
Lesmond (2005) indicated that volatility leads to a liquidity reduction as with the case of emerging markets besides the unexpected findings by Hearn and Piesse (2013), who suggested that the volatility of returns is negatively related to illiquidity measures.

\section{Methodology and data}

\subsection{Data}

The data for liquidity measures were collected from the FPTS website; the information on bid/ask prices dated back to June 2007. However, those for the period from June to August 2008 were not comprehensive (i.e. most of the bid prices are unavailable or reported to be lower than the ask ones), resulting in negative spreads and being thus excluded from the sampling (1). Next, the eliminated observations also included the months with less than 10 trading days (2), and the firms reflecting less than 20 months of transactions between September 2007 and November 2014 (3). Sample description is given below in Table 1 .

\section{Table 1}

Identification of liquidity measures

\begin{tabular}{lc}
\hline & Sample size \\
\hline Total observations between 1/2007 and 11/2014 & 44.739 \\
Negative bid-ask spreads (1) & -1.191 \\
Trading days < $10(2)$ & -303 \\
Months of transactions < 20 (25 firms) (3) & -244 \\
Final sampling & 43.001 \\
Number of firms in the sample & 643 \\
\hline
\end{tabular}

Data for macro variables were retrieved from the IMF's data on national accounts, consisting of monthly money supply, monthly CPI, and one-month term interbank rate offered by Vietnamese banking system. Statistics on industrial input values were obtained from GSO. 


\subsection{Variable description}

Most empirical research on the similar topic used the following measures for liquidity estimation (Marshall et al., 2013; Fong et al., 2014; Goyenko \& Ukhov, 2009; Hameed et al., 2010; Fernández-Amador et al., 2013).

Quoted spread (QUOS)

Such illiquidity estimator is computed as:

$$
\text { QUOS }=\frac{2 *(\text { ask }- \text { bid })}{(\text { ask }+ \text { bid })}
$$

A higher quoted spread indicates higher round trip transaction costs, and the market, therefore, is more illiquid.

Stock turnover ratio (TURNOVER)

The ratio can be defined as:

$$
\text { TURNOVER }=\frac{\text { Monthly total value traded }}{\text { Monthly average shares executed }}
$$

Amidhud's measure of illiquidity

Amihud's (2002) price sensitivity is calculated as follows:

$$
A \text { MIHUD }=10^{9} \cdot \frac{\left|\mathrm{R}_{\text {id }}\right|}{\mathrm{V}_{\text {id }}}
$$

where $R_{i d}$ denotes volatility in price of stock $i$ on day $d$ and $V_{i d}$ is trading volume of stock $i$ on day $d$.

This measure is based on the use of price sensitivity to estimate the degree of impact of transactions on price. A higher level of price sensitivity than that of the trading volume implies higher illiquidity reflected by the market and vice versa.

Proportion of zero returns (ZEROS)

According to Lesmond et al. (1999), the proportion is determined as follows:

$$
\text { ZEROS }=\frac{\text { Number of trading days with zero volume in month } t}{\text { Total number of trading days in month } t}
$$


A high cost of transaction would prevent the investors from their transactions to exploit available private information, thus causing a high proportion of illiquid stocks on the trading days with zero returns.

For the daily-based measures such as QUOS, TURNOVER, and AMIHUD, an average value of the days within a month is taken to achieve monthly data on liquidity for each stock, and an average value of all the studied stocks, subsequently calculated to obtain liquidity of the market in that month. Since the measure of ZEROS is based on monthly data, its average is taken to simply determine the zero returns for a specific month.

Monetary variables and research hypotheses

This study employs M2 growth and monthly interbank rates, calculated by taking average for the trading days within a month, as proxies for monetary policy variables.

In accordance with Brunnermeier and Pedersen's (2009) reasoning, market liquidity will rise if market participants gain access to financing sources more conveniently and in a less costly manner. Along with the empirical findings from Chordia et al. (2001), Chordia et al. (2005), and Fernández-Amador et al. (2013), the following hypotheses can be proposed:

$H_{1}$ : An unexpected increase in money supply is conducive to increased market liquidity.

$\mathrm{H}_{2}$ : An unexpected increase in interest rates is conducive to decreased market liquidity.

\section{Macro variables}

Growth in industrial production is used to measure productivity of the economy, positive shocks of the growth is expected to positively affect liquidity.

Inflation is scaled by volatility in monthly CPI. Shocks of inflation are expected to negatively affect liquidity.

Market returns are calculated by monthly average returns on the basis of equal proportions of all stocks in the studied sample. Unexpected volatility in the returns is predicted to positively affect market liquidity.

Monthly average standard deviation of the studied stocks is also adopted in volatility estimation. Shocks of the standard deviation are expected to negatively affect liquidity. 


\subsection{Research model}

Since there are mutual interactions between macro variables and liquidity measures, as shown by prior theories and empirical findings, this study employs VAR models to capture their effects at the market level with monthly data. VAR treats all variables as being endogenous, which were also addressed by other studies on liquidity (Chordia et al., 2005; Goyenko \& Ukhov, 2005; Goyenko \& Ukkhov, 2009; Fernández-Amador et al., 2013). The VAR model, which involves six endogenous variables with $p$ as lag length, can be presented as below:

$$
\mathrm{y}_{\mathrm{t}}=\mathrm{c}+\mathrm{A}_{1} \cdot \mathrm{y}_{\mathrm{t}-1}+\mathrm{A}_{2} \cdot \mathrm{y}_{\mathrm{t}-2}+\cdots+\mathrm{A}_{\mathrm{p}} \cdot \mathrm{y}_{\mathrm{t}-\mathrm{p}}+u_{\mathrm{t}}
$$

where $y_{t}$ is a $6 \times 1$ vector of endogenous variables, $c$ is a $6 \times 1$ vector of constants, $A_{i}$ is a (6xp) matrix, and $u_{t}$ is a $6 \mathrm{x} 1$ vector of residual terms. The lag length $p$ of each VAR model is determined in isolation.

To analyze the findings from VAR models in this study, impulse response function and variance decomposition are then used. Cholesky decomposition is intended to observe in what way and how long the unexpected shocks of each variable influence the others, and for the Cholesky decomposition, the order of variables is such that the variable before will have impact on the one that follows it. In light of the earlier studies of Chordia et al. (2005), Goyenko and Ukhov (2009), and Fernández-Amador et al. (2013), the macro variables are first arranged; next come the market ones (standard deviation and returns), and finally, the proxies for liquidity.

Different VAR models come in line with four liquidity measures and two monetary variables. These are ordered as follows:

IIP LAMPHATIMF M2_CHANGE/DVNIBOR STD R LIQUIDITY

where IIP is industrial production growth, a proxy for economic growth; LAMPHATIMF is inflation rate; M2_CHANGE is growth in money supply; DVNIBOR is volatility of monthly average interbank rate; STD is volatility of stock market; R is average market returns; and LIQUIDITY denotes liquidity measures, including DQUOS, DLNAMIHUD, DZEROS, and TURNOVER.

\section{Research results}

\subsection{Correlations between the indicators of liquidity}


Now that liquidity is a factor with a range of defining characteristics that cannot be captured by one proxy alone, it should be estimated by various measures as earlier suggested in the context of Vietnam's stock market. Noting that except for TURNOVER, which serves as a liquidity measure, the others are significantly associated with illiquidity, the author expects positive relations among the illiquidity measures besides their negative correlations with TURNOVER.

Table 3 displays different correlations among the measures with the use of monthly data. Correlations of the other ones are found to be completely as expected and are also statistically significant.

\section{Table 3}

Correlations between liquidity measures

\begin{tabular}{lccc}
\hline \multirow{2}{*}{ AMIHUD } & QUOS & AMIHUD & ZEROS \\
\cline { 2 - 4 } ZEROS & 0.9394 & & \\
& 0.0000 & & \\
TURNOVER* & 0.9135 & 0.9435 & \\
& 0.0000 & 0.0000 & -0.5462 \\
& -0.6246 & -0.5624 & 0.0000 \\
\hline
\end{tabular}

*Data for TURNOVER were only collected until December 31, 2013.

\subsection{Empirical results}

Stationarity test shows that except for QUOS, AMIHUD, and ZEROS, all the variables are stationary in levels. First differences are taken for non-stationary series to make them stationary before VAR estimates. Next, optimal lag lengths are selected based on AIC (Akaike Information Criterion) and SIC (Schwarz Information Criterion). Then, the analyses below are to be reported after different tests on stationarity, optimal lag length, autocorrelation of residuals, model stability, and variance decomposition are conducted to ensure the robustness of the model. The detailed results of VAR model estimates are performed in the following sections.

\section{Monetary policy and liquidity}

This section presents the response of liquidity estimators to the shocks of monetary policy, which is proxied by money supply. The results of Figure 1 indicate that a positive 
shock of standard deviation in the money supply volatility does not have any significant impact on TURNOVER at any lag length. Similarities are also shared with such other measures as DQUOS, DLNAMIHUD, and DZEROS as illustrated in Figure 2-4. The effects of money supply shocks on the liquidity measures are not statistically significant within the two standard deviation limits. When average interbank rate is used to proxy for monetary policy instead of the money supply, the results are uncannily similar.
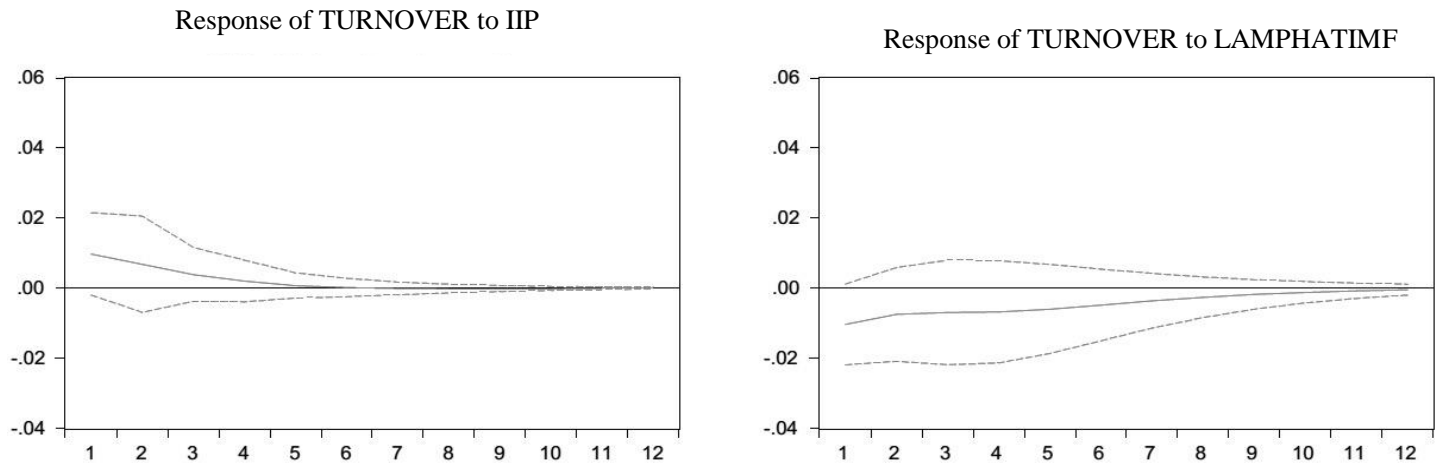

Response of TURNOVER to M2_CHANGE

Response of TURNOVER to STD
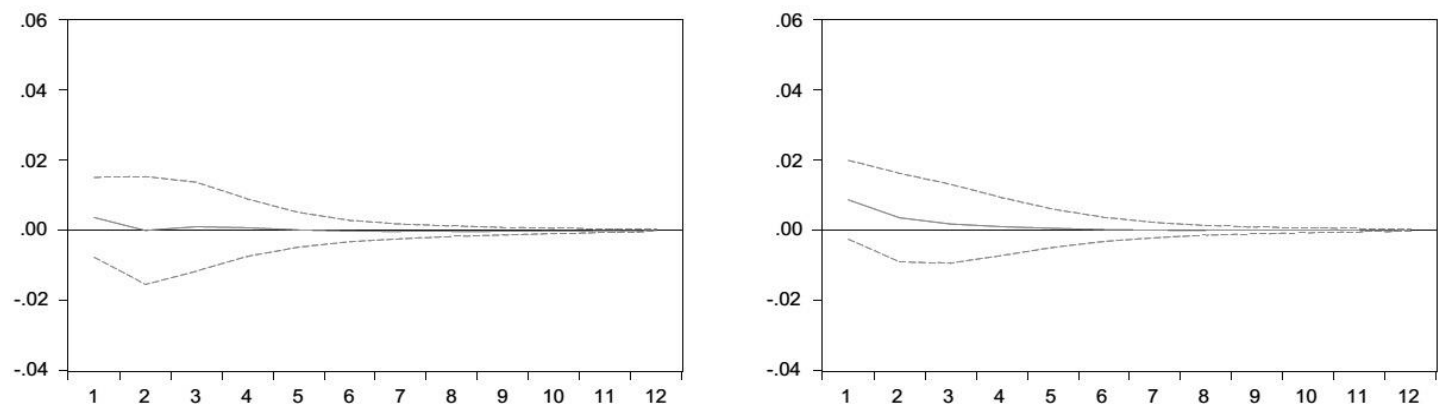

Response of TURNOVER to $\mathrm{R}$

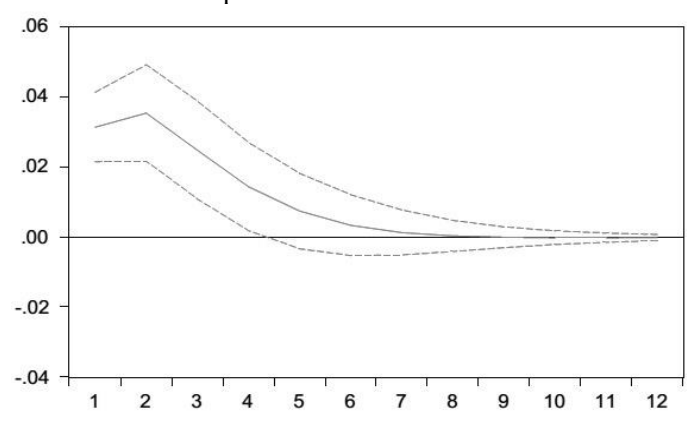

Response of TURNOVER to TURNOVER

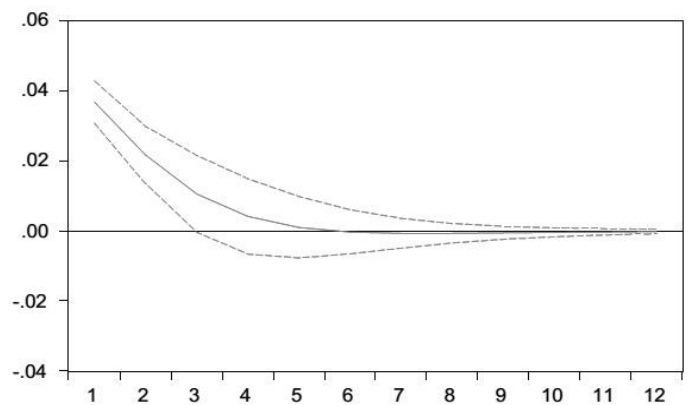

Figure 1. Impulse response of TURNOVER 


\section{Macro variables and liquidity}

Figure 1 illustrates that a shock of growth in industrial production results in a positive impact on TURNOVER with a 95\% confidence interval and a lag length of one month. Nevertheless, this response soon fades away at a two-month lag length, while at a fivemonth length it becomes totally insignificant. On the other hand, a rise in inflation shock negatively affects TURNOVER in the short run. This effect is statistically significant at one-month lag length, but is weakened over the following lags.

The results of impulse response of DQUOS (Figure 2) suggest that a positive shock of the standard deviation of industrial production growth contributes to a reduction in DQUOS at certain lags, and these effects are statistically significant. However, they gradually wear off and converge toward zero from the second term onward. The shock of inflation leads to increased DQUOS after lags while becoming relatively stable in the second month and then weakened.

Figure 3 demonstrates the impulse response of DLNAMIHUD. Market liquidity improves after a positive shock of industrial production growth, yet this effect is ephemeral in the second term and insignificant afterward. Inflation increases DLNAMIHUD or reduces the liquidity; the impact is statistically significant and is even steadily increased until the second term before becoming lessened and insignificant in the following months.

A positive shock of industrial production, as shown in Figure 4, reduces DZEROS over certain lags; the effects diminish but are significant until the following months and then become negligible. Meanwhile, a shock of inflation does not significantly influence DZEROS. The listed results are similar to those achieved when the interbank rate is employed instead of money supply. The consistency is also reflected, given an unexpected positive value of industrial production, which also causes decline in DZEROS and/or increase in liquidity, and no impact is produced on DZEROS of positive shocks of inflation. 

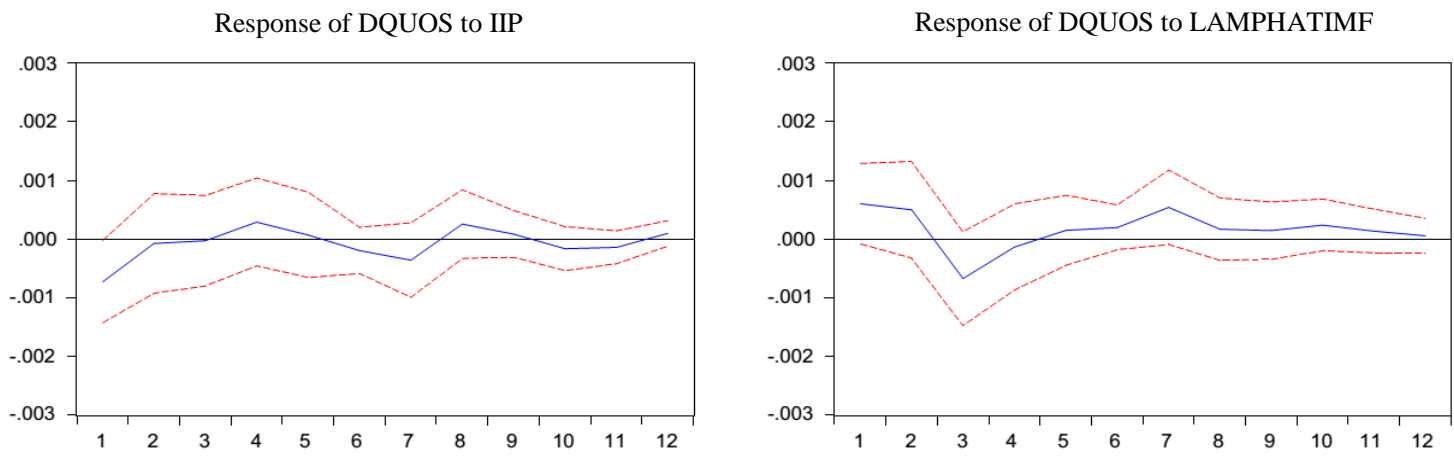

Response of DQUOS to M2_CHANGE

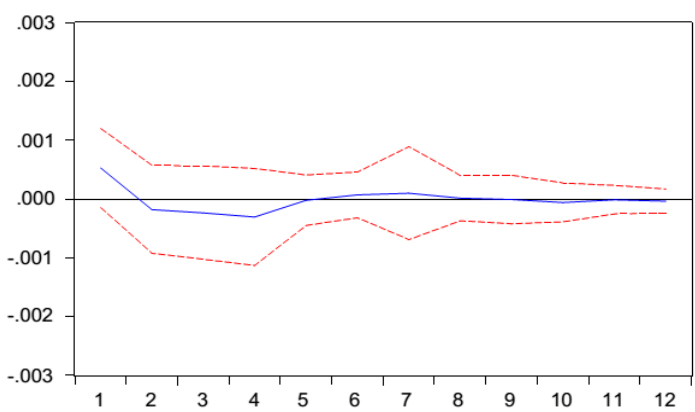

Response of DQUOS to STD

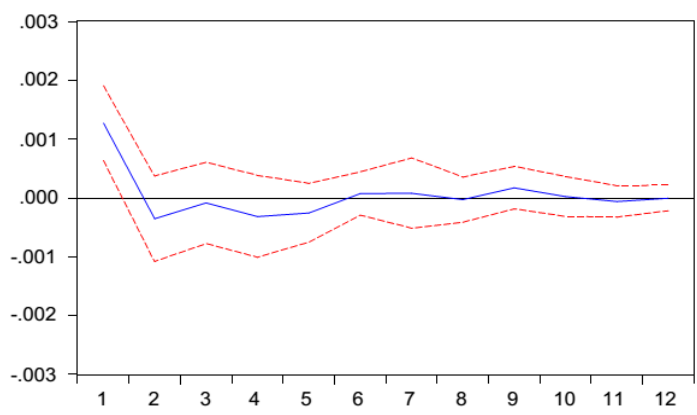

Response of DQUOS to R

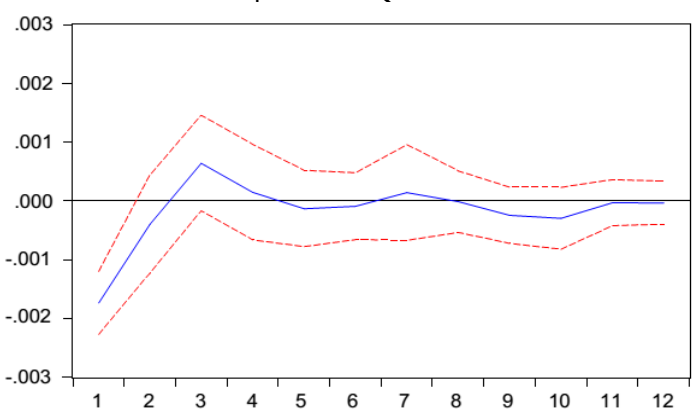

Response of DQUOS to DQUOS

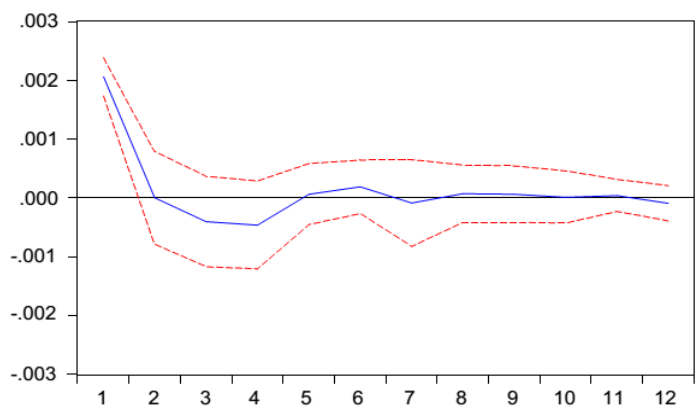

Figure 2. Impulse response of DQUOS

\section{Market variables and liquidity}

The results of impulse response function show that the shock of volatility in returns increases TURNOVER although it is not statistically significant. Additionally, the rate of returns has a profound impact on liquidity as expected. Specifically, when there is a shock of increased returns in the stock market, TURNOVER will markedly rise at a lag 
length of one month. Even though this effect grows weaker, it remains statistically significant until four-month lag.

The standard deviation has the most powerful impact on DQUOS. As such, a positive shock of the standard deviation increases DQUOS sharply after a month, yet this effect greatly diminishes at two lags. Although a positive shock of returns reduces DQUOS after a month, the impact is gradually lessened in the second month, and after the third month no influence can be found.
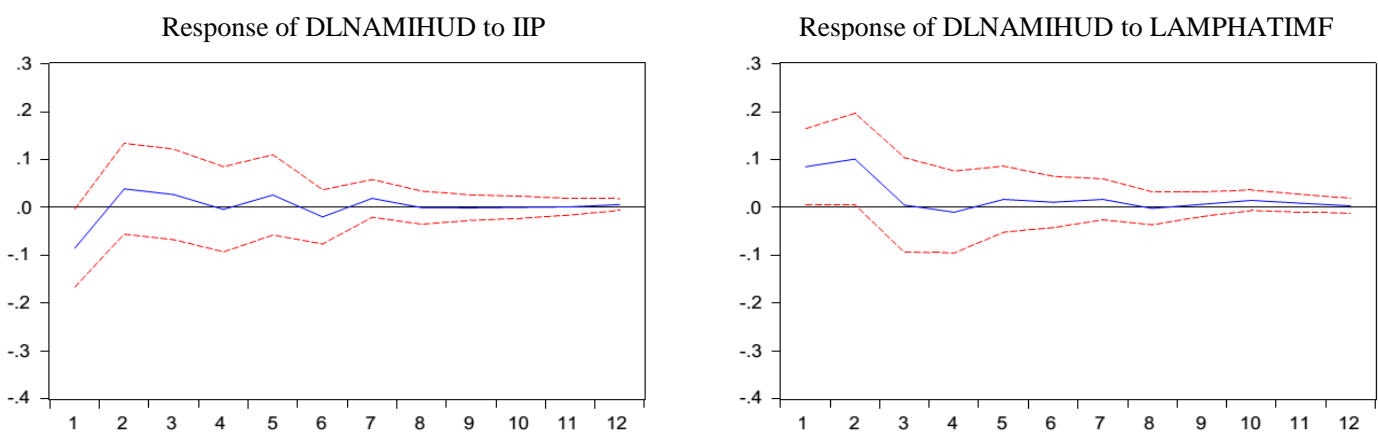

Response of DLNAMIHUD to M2_CHANGE

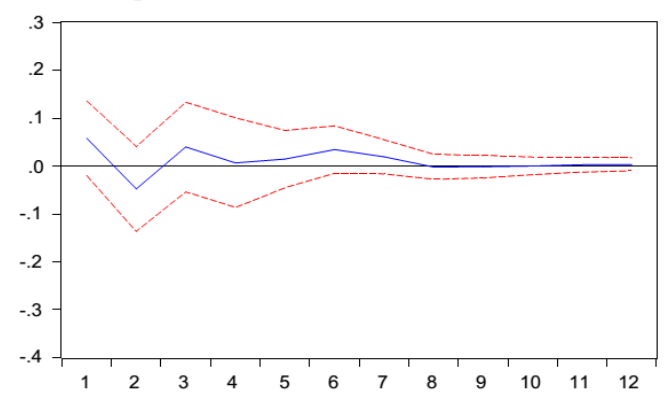

Response of DLNAMIHUD to STD
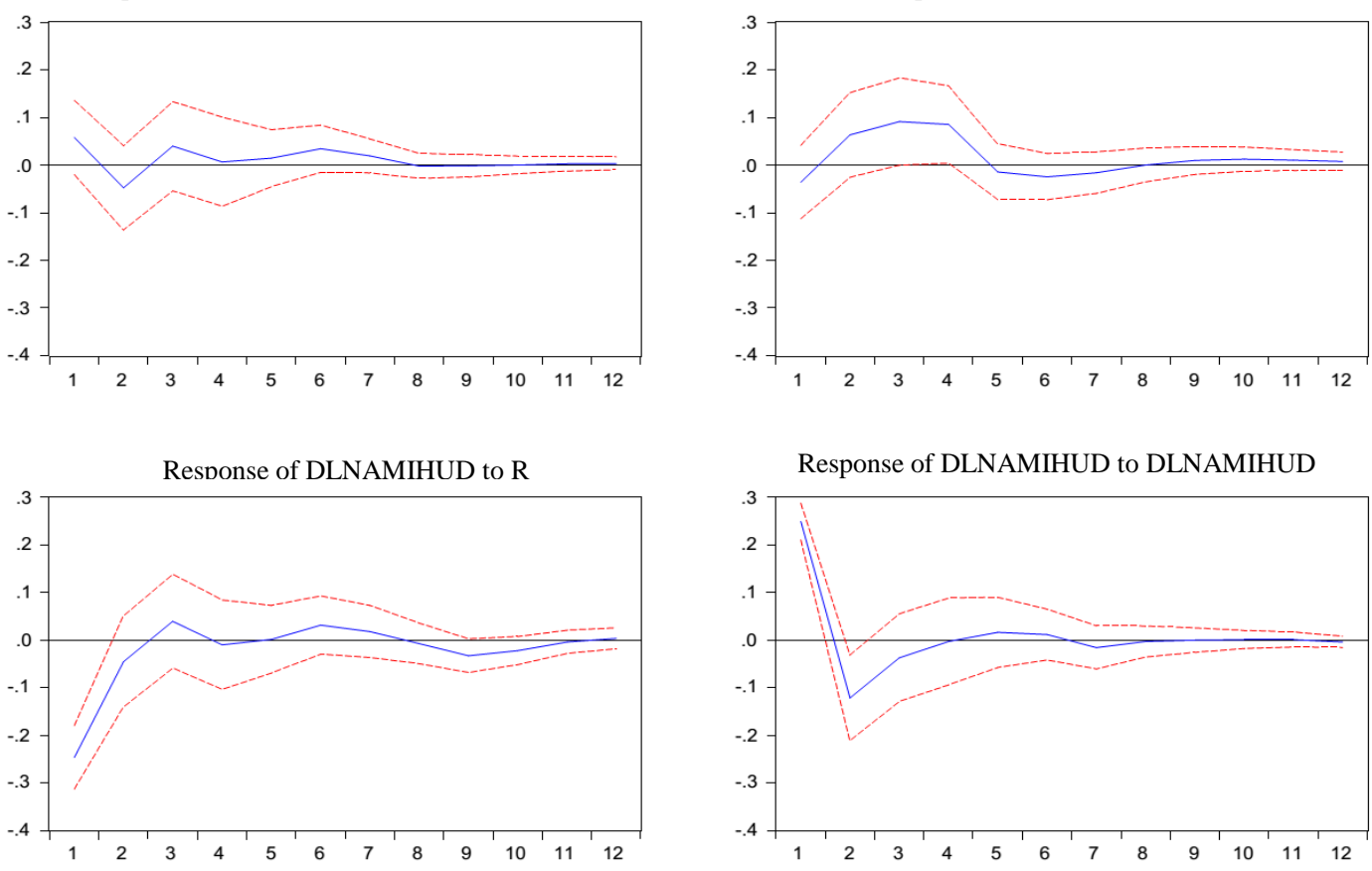

Figure 3. Impulse response of DLNAMIHUD 
Concerning DLNAMIHUD measure, a shock of standard deviation of the rate of returns does not generate any significant impact on DLNAMIHUD. Still, the return shocks lead to a decline in DLNAMIHUD at one lag length, and then the effect decreases bit by bit but remains significant until the third month.

Figure 4 indicates that DZEROS negatively responds to positive shocks of returns at a lag length of one month; the impact declines gradually in the second month and becomes smaller after that. Standard deviation has a strong influence on DZEROS, but astoundingly, the response does not produce expected signs. A positive shock of volatility in returns drastically reduces DZEROS in the first month. However, the response quickly turns to be positive in the following months before no significant impact can be recorded, starting from the fourth month. The author argues that as for DZEROS measures, when there is an increase in volatility, investors may be attracted to transactions where they could capitalize on the market returns due to large fluctuations, particularly when the market is dominated by a vast majority of individual investors with a lack of discipline in their trading activities. 
Response of DZEROS to IIP

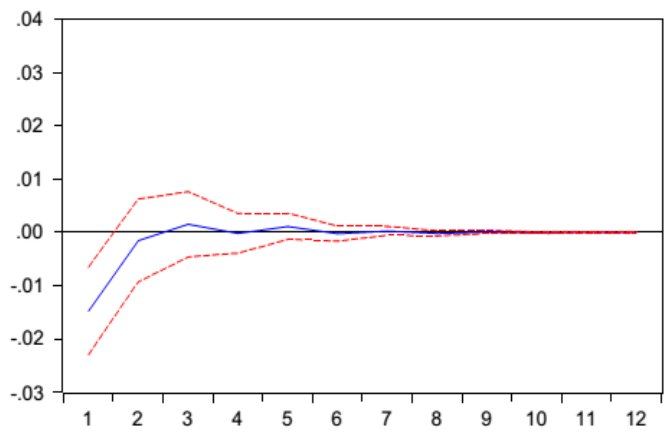

Response of DZEROS to M2_CHANGE

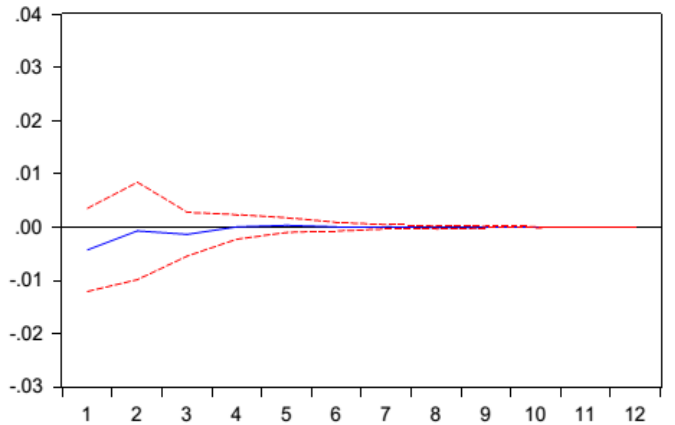

Response of DZEROS to R

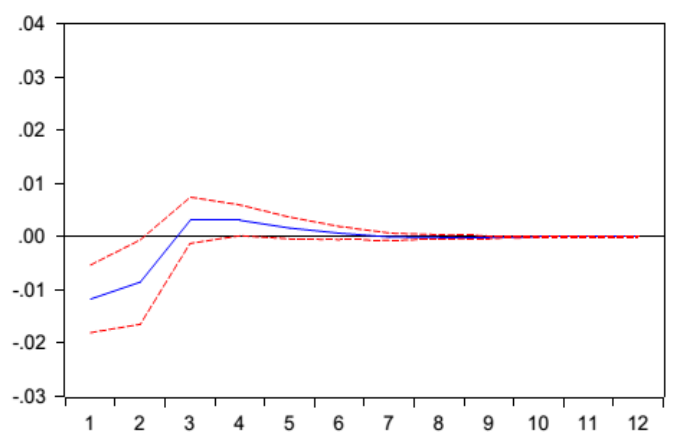

Response of DZEROS to LAMPHATIMF

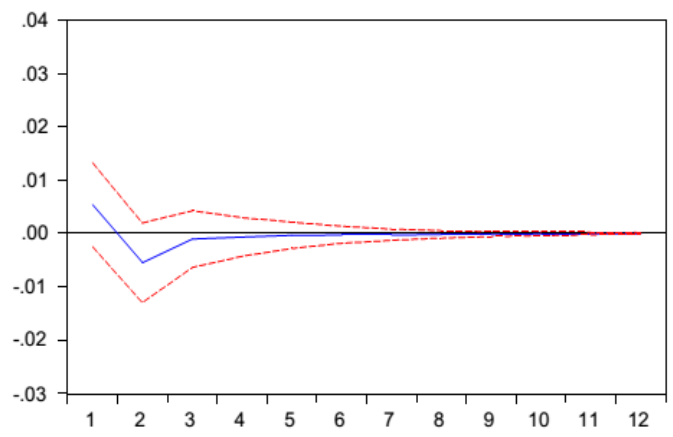

Response of DZEROS to STD

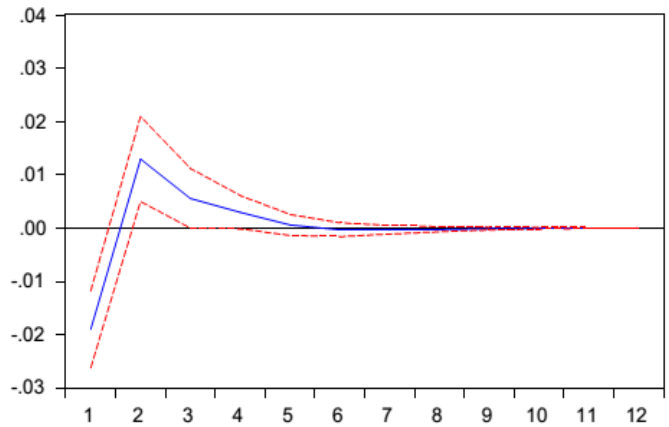

Response of DZEROS to DZEROS

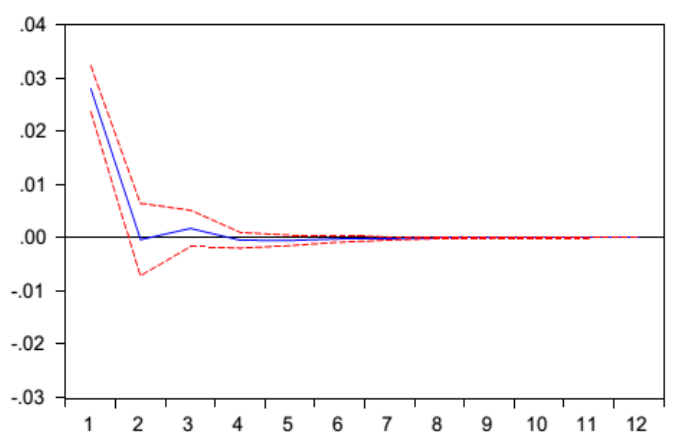

Figure 4. Impulse response of DZEROS 


\section{Conclusion and implications}

\subsection{Conclusion}

From the above analyses of different liquidity/illiquidity measures, the following concluding remarks can be provided:

First of all, shocks of the factors that represent monetary policy exert no impact on market liquidity. This result does not support the theories and empirical evidence as have been found across the global securities markets.

Next, shocks of industrial production have expected, significant, and consistent effects on liquidity for all liquidity estimators.

Furthermore, unexpected information on inflation does affect market liquidity, which has been found to be statistically significant in three out of four liquidity measures.

Importantly, shocks of volatility are shown to influence the two measures of illiquidity, but the effects produce opposite results.

Finally, the impact of shocks of returns on liquidity, as exhibited by the empirical findings, is profound and consistent for all the estimators, and this outcome is in line with the author's expectations.

\subsection{Policy implications}

Unlike most empirical evidence from foreign stock markets, two monetary policy variables (M2 growth and interbank rate volatility) produce no significant impact on market liquidity whatsoever. Such a marked discrepancy should be well perceived as monetary policy, among all macro policies, commonly serves to alter the liquidity of the market. Considering Vietnam's regulations, we shall conclude that these empirical findings are of no irrationality. A positive shock of money supply, theoretically speaking, raises the likelihood of capital access by investors, and similarly, a positive shock of interest rate pushes up their costs of financing. As a result, those who suffer from capital deficit would find certain obstacles to trade on margin, or using margin accounts becomes eminently undesirable.

In Vietnam the regulations on investors' use of margin accounts have lately come into effect; however, those specifically on the accepted amount of credit provided for investors are controlled within strict constraints imposed by the central bank. Most of the research stages indicate that the access to credit financing exposes severe limitations. 
Particularly, pursuant to Directive No. 03/2007/CT-NHNN issued by the State Bank of Vietnam on controlling the amount and quality of credit and loans for securities investment and trading, the capital limit for securities loans should be less than $3 \%$ of the total outstanding loans of each bank. After that, in 2008 Decision No. 03/2008/QDNHNN regulated that the securities lending amount cannot exceed $20 \%$ of charter capital of each bank, which merely has no direct relation to money supply.

Accordingly, expecting extensive alterations to monetary policy to better market liquidity will not become realistic until the aforementioned barriers are altogether removed. It is important for the policy makers to consider changing the regulations along with the self-adjusting market mechanism and thereby to aim at efficient allocation of capital sources while certain levels of risk posed to credit institutions can be hedged around.

Evidence on positive shocks of industrial production positively affecting liquidity coupled with positive shocks of inflation that involve liquidity decline implies that facilitating economic growth and curbing inflation are essential to maintain the market liquidity.

Furthermore, unexpected variances in market returns contribute significantly to liquidity improvement, which, as can be suggested, also results from investors' returnseeking behavior. Thus, creating positive shocks of returns, irrespective of whether investors in their transactions gain sufficient information, manifests itself as a determinant of increased liquidity

\section{References}

Alrabadi, D. W. H. (2012). An analysis of aggregate market liquidity: The case of Amman Stock Exchange. International Business Research, 5(5), 184-194.

Amihud, Y. (2002). Illiquidity and stock returns: Cross-section and time-series effects. Journal of Financial Markets, 5(1), 31-56.

Amihud, Y., \& Mendelson, H. (1986). Asset pricing and the bid-ask spread. Journal of Financial Economics, 17(2), 223-249.

Baker, M., \& Stein, J. C. (2004). Market liquidity as a sentiment indicator. Journal of Financial Markets, 7(3), 271-299.

Benston, G. J., \& Hagerman, R. L. (1974). Determinants of bid-asked spreads in the over-the-counter market. Journal of Financial Economics, 1(4), 353-364. 
Brunnermeier, M. K., \& Pedersen, L. H. (2009). Market liquidity and funding liquidity. Review of Financial Studies, 22(6), 2201-2238.

Choi, W. G., \& Cook, D. E. (2006). Stock market liquidity and the macroeconomy: Evidence from Japan. Monetary Policy with Very Low Inflation in the Pacific Rim, 15, 309-340.

Chordia, T., Roll, R., \& Subrahmanyam, A. (2001). Market liquidity and trading activity. The Journal of Finance, 56(2), 501-530.

Chordia, T., Sarkar, A., \& Subrahmanyam, A. (2005). An empirical analysis of stock and bond market liquidity. Review of Financial Studies, 18(1), 85-129.

Chordia, T., Sarkar, A., \& Subrahmanyam, A. (2008). Liquidity and market efficiency. Journal of Financial Economics, 87(2), 249-268.

Copeland, T. E., \& Galai, D. (1983). Information effects on the bid-ask spread. The Journal of Finance, 38(5), 1457-1469.

Do, D. M. (2010). Some ideas on sustainable growth of Vietnam's stock market at the present (in Vietnamese). Nghien Cuи Kinh Te, 385, 44-50.

Eisfeldt, A. L. (2004). Endogenous liquidity in asset markets. The Journal of Finance, 59(1), 1-30.

Fernández-Amador, O., Gächter, M., Larch, M., \& Peter, G. (2013). Does monetary policy determine stock market liquidity? New evidence from the euro zone. Journal of Empirical Finance, 21, 54 68.

Fong, K. Y. L., Holden, C. W., \& Trzcinka, C. (2014). What are the best liquidity proxies for global research? Retrieved from http://ssrn.com/abstract $=1558447$

Goyenko, R. Y., \& Ukhov, A. D. (2009). Stock and bond market liquidity: A long-run empirical analysis. Journal of Financial and Quantitative Analysis, 44(1), 189-212.

Hameed, A., Kang, W., \& Viswanathan, S. (2010). Stock market declines and liquidity. The Journal of Finance, 65(1), 257-293.

Hearn, B., \& Piesse, J. (2013). Firm level governance and institutional determinants of liquidity: Evidence from Sub Saharan Africa. International Review of Financial Analysis, 28, 93-111.

Jawadi, F., Arouri, M., \& Nguyen, D. (2010). Global financial crisis, liquidity pressure in stock markets and efficiency of central bank interventions. Applied Financial Economics, 20(8), 669680.

Kale, J. R., \& Loon, Y. C. (2011). Product market power and stock market liquidity. Journal of Financial Markets, 14(2), 376-410.

Kyle, A. (1985). Continuous autions and insider trading. Econometrica, 53(6), 1315-1336.

Lesmond, D. A. (2005). Liquidity of emerging markets. Journal of Financial Economics, 77(2), 411452. 
Lesmond, D. A., Ogden, J. P., \& Trzcinka, C. A. (1999). A new estimate of transaction costs. Review of Financial Studies, 12(5), 1113-1141.

Marshall, B. R., Nguyen, N. H., \& Visaltanachoti, N. (2013). Liquidity commonality in commodities. Journal of Banking \& Finance, 37(1), 11-20.

Nguyen, T. P. (2012). Impact of liquidity on returns on stocks listed in Vietnam's stock market. Journal of Economic Development, 264, 33-39.

Rhee, S. G., \& Wang, J. (2009). Foreign institutional ownership and stock market liquidity: Evidence from Indonesia. Journal of Banking \& Finance, 33(7), 1312-1324.

Roll, R. (1984). A simple implicit measure of the effective bid-ask spread in an efficient market. The Journal of Finance, 39(4), 1127-1139.

SBV. (2007). Directive No. 03/2007/CT-NHNN on controlling the amount and quality of credit and loans for securities investment and trading, aimed at controlling inflation and boosting economic growth. Retrieved from http://thuvienphapluat.vn/van-ban/Tien-te-Ngan-hang/03-2007-CTNHNN-83994.aspx

SBV. (2008). Decision No. 03/2008/QD-NHNN on the lending and discount of valuable papers for securities investment and trading. Retrieved from http://lawfirm.vn/?a=doc\&id=1493

Subrahmanyam, A. (1994). Circuit breakers and market volatility: A theoretical perspective. The Journal of Finance, 49(1), 237-254.

Watanabe, A. (2004). Macroeconomic sources of systematic liquidity. Retrieved April 15, 2015 from http://ssrn.com/abstract=598781.html 